\title{
Spatiotemporal Characteristic of Biantun Toponymical Landscape: Evolution of Biantun Culture in Yunnan,China
}

\section{Fei Zhao}

School of Earth Science, Yunnan University

Jingzhi Cai

School of Earth Science, Yunnan University

Chen Zhang

State Key Laboratory of Information Engineering in Surveying Mapping and Remote Sensing

Guize Luan

School of Earth Science, Yunnan University

Yao Fu

School of Earth Science, Yunnan University

Zhiqiang Xie ( $\nabla$ xzq_2019@ynu.edu.cn )

School of Earth Science, Yunnan University

\section{Research Article}

Keywords: Biantun culture, toponymical landscape, spatiotemporal characteristics, integration index

Posted Date: April 16th, 2021

DOl: https://doi.org/10.21203/rs.3.rs-422855/v1

License: (c) (1) This work is licensed under a Creative Commons Attribution 4.0 International License.

Read Full License

Version of Record: A version of this preprint was published at Scientific Reports on December 1st, 2021.

See the published version at https://doi.org/10.1038/s41598-021-03271-2. 


\title{
1 Spatiotemporal Characteristic of Biantun toponymical
}

2 landscape: evolution of Biantun culture in Yunnan,

3 China

4

\author{
Fei Zhao', Jingzhi Cai', Chen Zhang ${ }^{2}$, Guize Luan', Yao Fu', Zhiqiang Xie ${ }^{1}$ \\ ${ }^{1}$ School of Earth Science, Yunnan University, Kunming 650091, China; \\ ${ }^{2}$ State Key Laboratory of Information Engineering in Surveying, Mapping and Remote Sensing, Wuhan \\ University, Wuhan 430079, China \\ Corresponding author: Zhiqiang Xie (e-mail: xzq_2019@ynu.edu.cn).
}

\begin{abstract}
The unique geographical environment of Yunnan Province in China and large-scale waves of Han migration during the Ming Dynasty contributed to the emergence and development of the Biantun culture. The toponym is the carrier of the Biantun culture: it records the integration process between the Central Plains and native Yunnan cultures. Based on the GIS spatiotemporal analysis of toponyms in Yunnan, this study reproduced the settlement characteristics of Biantun toponyms (BTT) and the spatial development of the Biantun culture in the Ming and Qing Dynasties. In addition, we've developed toponymical landscape index to represent the degree of spatial integration between the BTT and ethnic minority toponyms in Yunnan and explore the spatial characteristics of the integration of Han immigrants and local ethnic minorities. The results show that the spatial distribution of the BTT is consistent with the site selection of the central plains immigrants station troops to open up wasteland in Yunnan during the Ming and Qing Dynasties, and the centroids of BTT spread to outskirts and intermontane area from central towns. In Dali, Kunming, Qujing regions, etc present the distribution characteristics of the mixed of BTT and ethnic minority toponyms, and a higher degree of Sinicization in the central urban areas. This study used GIS applications for historical and cultural research and established the connection among Biantun culture and spatiotemporal data. Exploring evolution of Biantun cultural development through the spatial characteristics of toponymical landscape can help adjust policies for he development and protection of the Biantun cultural resources.
\end{abstract}

Keywords: Biantun culture; toponymical landscape; spatiotemporal characteristics; integration index

\section{Introduction}

Han immigrants who migrated to frontier areas in China underwent a process of settling in towns and villages, engaged in creative production, worked/lived with local ethnic groups, exchanged cultures, and developed in tandem, resulting in ethnic integration ${ }^{1}$. Biantun culture is a typical immigrant culture of cultivation and guarding borders formed by the Han people who migrated and settled in border areas; it merges their original Central Plains culture with those of border regions and national traditional cultures ${ }^{2}$. Yunnan is a border province that has been important for ethnic migration and cultural exchange since ancient times. During the Ming Dynasty, military immigrants arrived in Yunnan because of wars. The population structure, ethnic distribution, production relations, political system and cultural orientation of Yunnan society experienced epoch-making changes as Han immigrants settled in various localities and gradually integrated with local ethnic groups. Starting with Yongsheng County, Yunnan Province has become the most representative area for research into Biantun culture. 
The study of Biantun culture started late, most existing studies are limited to reviews and discussions on cultural connotation and historical evolution. The Biantun toponyms (BTT) arose from the development of the Biantun culture. Toponyms not only represent geographical locations, but also represent spatial entities. In different time scales, in addition to their original meanings, there are also local historical, cultural, social, and national meanings. The 'GIS + toponym' research model for relearning place names from a new perspective, and in particular, toponyms with spatiotemporal information characteristics, we carry out the study of Yunnan Biantun culture in this model. Many scholars have made rich research results in this field. ${ }^{3-10}$. The geographer David Mark expanded the investigation of toponyms from ethnophysiography research on Malay names, mountain names, and other features ${ }^{11}$. Studies of minority place names have included the use of GIS' geometric center analysis and spatial orientation distribution technology to obtain a possible historical distribution of Zhuang toponyms in Guangxi Province ${ }^{12,13}$. GIS was used to analyze the spatial patterns of Zhuang, Cantonese, Min Nan, and Hakka toponyms, and to compare historical data between ancient and modern times for the study of historical population and landscape evolution of various ethnic groups 14. Wang et al. explored the spatiotemporal evolutionary characteristics of county-level administrative toponyms and cultural landscapes in China's eastern plains ${ }^{15}$.

Toponym symbol have inherited the unique local historical culture in the long process of historical development. The distinctive naming method of BTT makes it an obvious landmark of Biantun culture. The study of toponymical landscape can provide a theoretical basis for the research on the spread of Yunnan Biantun culture and the development of social structure and ethnic integration.

\section{$61 \quad$ Materials and Methods}

\section{BTT data}

Yunnan is located on the southwestern border of China (Fig. 1). During the early Ming Dynasty, wars in Yunnan were frequent and living conditions were extremely unstable. During the Hongwu years, military immigration of Han ethnic migrants occurred on a large scale. During Yunnan unification and while consolidating the southwest frontier, the institutionalization of land reclamation and crop farming by stationed troops resulted in the mass migration of Han people to Yunnan. Most of the military migrants were concentrated in central towns; Tuntian (where troops are stationed and opened up wasteland) districts were concentrated in the suburbs of important towns. 


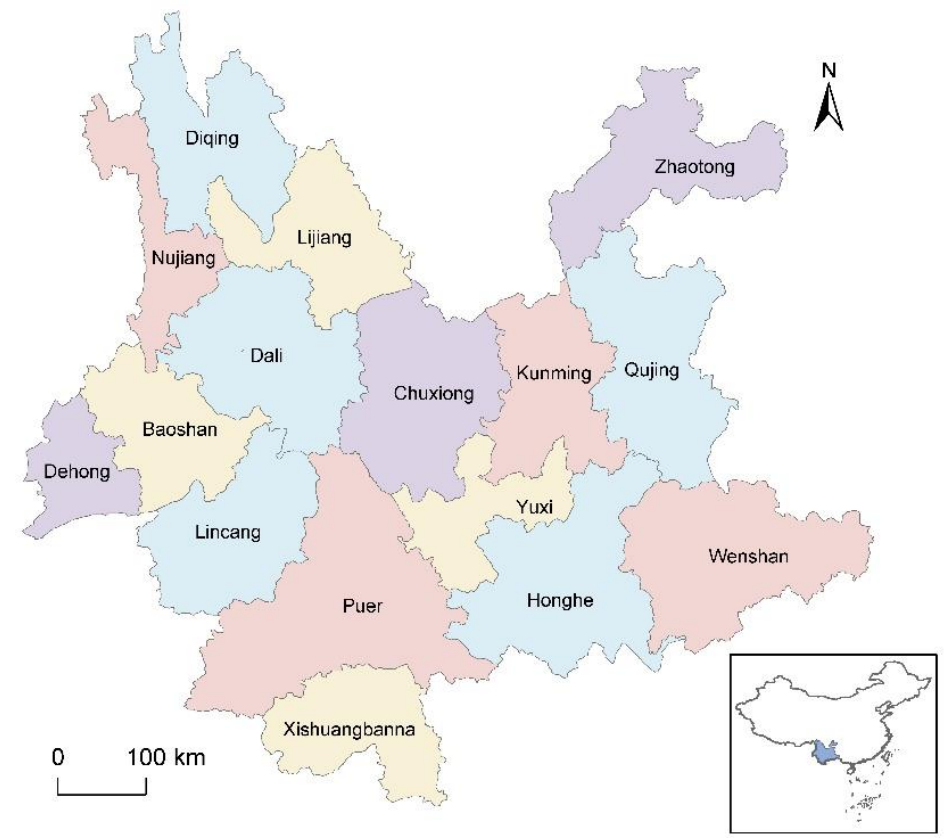

Fig.1 Location of Yunnan

According to the Ming Dynasty system, Ying was the basic unit of the army, and Tun was an army resettlement system managed by the metropolis ${ }^{16}$. Halfway through the Ming Dynasty, conditions in Yunnan began to stabilize. Initially, Han immigrants began settling large-scale settlements on the outskirts of towns, followed by remote areas of flat land. The main Tuntian sites of the middle Ming Dynasty were named based on military units, including Wei, Suo, Qianhu, and Baihu, where the grade hierarchy was Wei $>$ Suo $>$ Qianhu $>$ Baihu. According to an order from Zhu Yuanzhang (the Ming emperor), the armies of Wei and Suo had to be self-sufficient; this required oneseventh of the army to farm and one-third to guard the city. Military yards around the Wei and Suo provided an economic source. Furthermore, the military yards of Yunnan reflected the emergence of toponyms during the middle Ming Dynasty, and were named after senior military chiefs' surnames and suffixed with lower-level transportation trunk facilities and organization; for example, "post" (Yi), "fort" (Bao), "shop" (Pu), "sentry" (Shao), and others.

Beginning half-way through the Ming Dynasty and towards its end, along with the comprehensive development of immigrant agriculture, military yards moved to city outskirts, intermontane basins, and to mid-mountain areas. The original large-scale military yards were not suitable for agricultural development and production under the new terrain, which prompted the original basic organization of the Tuntian to shrink, and small organizational units such as $\mathrm{Qi}, \mathrm{Wu}$, and Guan to appear. The toponyms that appeared at this time included the surname of the chief of the Qi, the Guan, and the $\mathrm{Wu}$, and the lower-level organizational units.

By the end of the Ming and early Qing dynasties, conditions in Yunnan were more stable; the population continued to increase and the branches of large clans began to spread. At this time, militarybased toponyms faded, and some toponyms added the word "village" (Cun) after the words used in the original military units. Owing to a series of insurrections and border conflicts during the Qing Dynasty, a large number of military immigrants moved to Yunnan and settled in rural areas. In addition, they followed the floating official system of the Ming Dynasty and the upsurge in commerce, resulting in a large number of settlements wherein the Han nationality and a minority nationality merged ${ }^{17}$. 
Through the integration of relevant historical materials and documents, thirteen types of place names (Yin, Tun, Wei, Suo, Baihu, Qianhu, Qi, Guan, Wu, Yi, Pu, Bao, and Shao) were selected in this study, with the Ming and Qing dynasties as the research time node. Based on the BTT screening procedure ${ }^{18-23}, 1563$ toponyms in Yunnan Province were extracted.

The second national toponymic census in China obtained the attribute content of place name origin (placeOrigi) and meaning (placeMeani), historical evolution (placeHisto), geographical entity overview and other attributes through data collation and field investigation. The meanings of toponyms indicate their natural, social, humanistic and economic significance. The historical evolution describes the changes in the creation and modification of toponyms. The information regarding Yunnan rural settlements, urban settlements, and mountain names was obtained from the National Database for Geographical Names of China (http://dmfw.mca.gov.cn/), as presented in Table 1.

Table 1 Toponym information of second national toponymic census in China

\begin{tabular}{|c|c|}
\hline Field name & Detail \\
\hline standard a & Daying \\
\hline placeType & Rural settlement \\
\hline placeOrigi & $\begin{array}{l}\text { Named for historical events. Also because of the Liangwang River around the vil- } \\
\text { lage, the former forest was lush and the scenery was beautiful, it was refined into } \\
\text { Huanxiu Village in the early Qing Dynasty, however the folk still call it Daying. }\end{array}$ \\
\hline placeMeani & $\begin{array}{l}\text { The Ming general Mu Ying conquered Queen Liang, and in the 19th year of } \\
\text { Hongwu (1386 A.D.), he stationed troops there, and the camp was large. }\end{array}$ \\
\hline placeHisto & $\begin{array}{l}\text { After the 19th year of Hongwu of Ming (1386), Mu Ying's troops had stationed } \\
\text { their troops and hoarded supplies here, and because of the large number of troops, } \\
\text { they were named Daying. }\end{array}$ \\
\hline lon & 102.827 \\
\hline lat & 24.7887 \\
\hline
\end{tabular}

Owing to changes in place names, current place names may not be identified by the aforementioned key words. Therefore, the following steps were used to determine whether the place name was a BTT:

(1) Identification of place name attributes.

Natural language processing integrates disciplines such as cognitive science, linguistics, and computer science to solve problems such as information retrieval, information extraction, and automatic abstraction. As a basic natural language processing technique, Chinese word segmentation recombines consecutive word sequences into word sequences according to certain specifications and performs preliminary attribute processing for screening of BTT ${ }^{24}$. The villages, urban settlements, and mountains formed by the places of stationed troops and military facilities during the Ming and Qing Dynasties were judged as the BTT and were extracted based on the keywords such as garrison, station troops, and set up sentry post. The creation time of toponym is extracted from the historical evolution field. If there is no exact year of the toponym in the field, the Tuntian time is extracted from the two fields of place name meaning and historical evolution.

If the creation time of toponym and Tuntian time are not known, gazetteers and related documents are checked and the time corresponding to the time of the local historical military immigrants is adopted.

\section{Research methods}


BTT are dot distributions. Based on the clustering characteristics, the spatial model of the BTT distribution in different periods can be studied using the density characteristics of its points. In this study, the kernel density estimation (KDE) method was used to map the spatial clustering characteristics of all BTT and the small spatial scales of BTT in different periods. Additional exploration of the overall trend of BTT based on the KDE method used a moving cell to estimate the density of a point or a line pattern. The density property of the location area can be obtained using $\mathrm{KDE}$, which is characterized by assigning weights to all points by using the kernel function to create a smooth distribution of results. The kernel density is calculated as follows:

$$
f(x)=\frac{1}{n h} \sum_{i=1}^{n} K\left[\frac{1}{h}\left(x_{i}-\bar{x}\right)\right]
$$

where $K[]$ is the kernel function, $n$ is the number of known points in the bandwidth range, $h>0$ is the bandwidth, and $x_{i}$ is the position coordinate on the point $\mathrm{i}(\mathrm{i}=1,2, \ldots, \mathrm{n})$.

Considering the complicated terrain of Yunnan, we selected a mountain range with large undulations to calculate the average distance between each pair, and finally selected bandwidths of 20 $\mathrm{km}, 30 \mathrm{~km}$, and $40 \mathrm{~km}$ for comparison (Fig. 2) to determine the optimal bandwidth and analyze the distribution characteristics of BTT. It can be observed from the figure that the maximum density value with a bandwidth of $20 \mathrm{~km}$ is 0.078 , the maximum density value with a bandwidth of $30 \mathrm{~km}$ is 0.043 , and the maximum density value with a bandwidth of $40 \mathrm{~km}$ is 0.034 . In KDE, the smaller the bandwidth, the greater the density value within the bandwidth, and more highlight the density value; the larger the bandwidth, the smaller the density value within the bandwidth and the smoother the density value gradient. With $30 \mathrm{~km}$ as the bandwidth, it can clearly identify the density center of BTT and reflect the degree difference of the kernel density of the toponym.

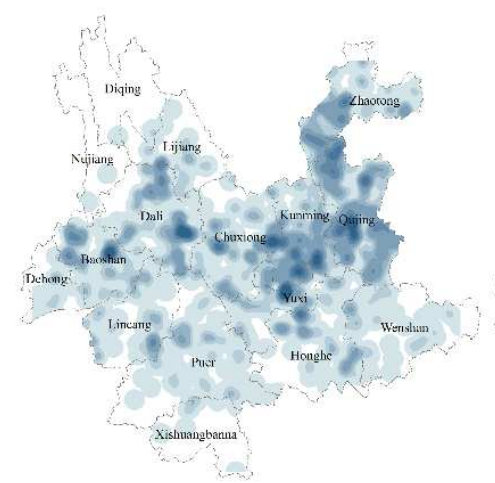

(a) bandwidth $=20 \mathrm{~km}$

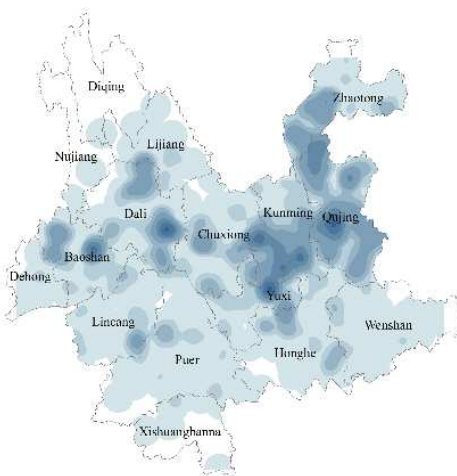

(b) bandwidth $=30 \mathrm{~km}$

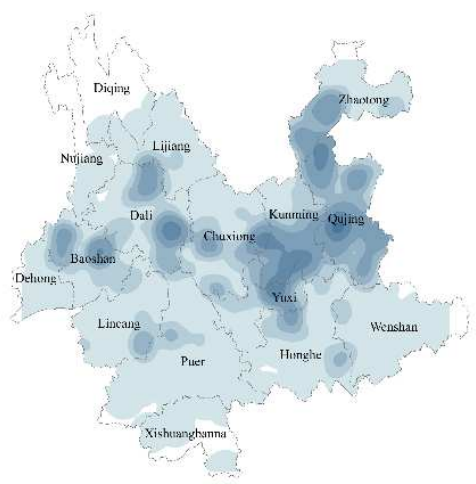

(c) bandwidth $=40 \mathrm{~km}$

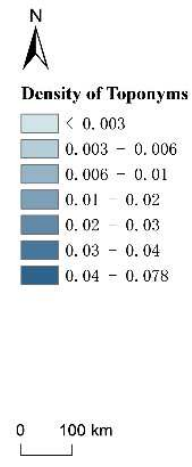

Fig.2 Kernel density of BTT with bandwidth of $20 \mathrm{~km}, 30 \mathrm{~km}, 40 \mathrm{~km}$

\section{Emerging Hot Spot Analysis}

Emerging hot spot analysis (EHSA) examines the clustering of points over time. It uses a space time cube to generate the analysis based on the Getis-Ord Gi* statistic ${ }^{25}$. A space-time cube creates layers where data is categorized by its $\mathrm{x}$ and $\mathrm{y}$ coordinates for its geographic location and $\mathrm{z}$ coordinates for its year. The space-time cube uses the Mann-Kendall trend test to determine the statistical significance of how the points are changing ${ }^{26}$. In this study, the input of the time step parameter was adjusted based on this algorithm; therefore, the time domain can be set flexibly. The analyses were performed in four time domains: early Ming (1368-1435), Mingzhong (1436-1582), Minghou (1583- 
1644), Qing Dynasty (1645-1912).

The Getis-Ord local statistic is given as

$$
\begin{gathered}
G_{i}^{*}=\frac{\sum_{j=1}^{n} w_{i, j} x_{j}-\bar{X} \sum_{j=1}^{n} w_{i, j}}{\sqrt{\frac{\left[n \sum_{j=1}^{n} w_{i, j}^{2}-\left(\sum_{j=1}^{n} w_{i, j}\right)^{2}\right]}{n-1}}} \\
\bar{X}=\frac{\sum_{j=1}^{n} w_{i, j}}{n}, S=\sqrt{\frac{\sum_{j=1}^{n} x_{j}^{2}}{n}-(\bar{X})^{2}}
\end{gathered}
$$

where $x_{j}$ is the attribute value for feature $j, w_{i, j}$ is the spatial weight between $i$ and $j, n$ is equal to the total number of feature, and the $G_{i}^{*}$ statistic is a z-score; no further calculations are required.

\section{Standard Deviation Ellipse}

The standard deviation ellipse (SDE) model is commonly used to analyze spatial distribution characteristics of a point data set; it also analyzes the direction and distribution of points. The long and short axes of the ellipse indicate the directions of maximum and minimum diffusion, respectively. The smaller the area, the closer the distribution is to the center of gravity and the more it represents a concentrated distribution. Elliptical deflection angles of $0 \% 180^{\circ}$ and $90^{\circ}$ indicate a dominant northsouth or east-west direction, respectively.

Integration index

The integration degree can be interpreted as pattern differentce of integration of the spatial distribution of the BTT and ethnic minority toponyms. First, extract the overall hierarchical cluster structure by clustering all toponym points, the distance density constrained clustering method based on Delaunay triangulation is used to extract the point cluster structure in this study ${ }^{27}$. According to the clustering results, the Voronoi region generated by the all toponym points is merged to obtain the distribution region of each point cluster. After counting the number of BTT and ethnic minority toponyms in each region of each point cluster, we denote $H_{i}$ as the integration degree of two kinds of toponyms in spatial distribution:

$$
H_{i}=\frac{n_{e}}{N_{i}}-\frac{n_{b}}{N_{i}}
$$

where $N i$ is the total number of toponyms in point cluster $i$, are the number of ethnic minority toponyms and BTT in the region, $H_{i}$ ranges from -1 to 1.

\section{Results and discussion}

\section{Spatiotemporal distributional characteristics of the BTT and Biantun cultural landscape}

The KDE was performed on all the BTT in Yunnan Province. As shown in Fig. 2 (b), the core (i.e., the highest kernel density distribution) is at the junction of Chuxiong, Kunming, Qujing, and Yuxi. The density center is in the northwest of the junction. The BTT cluster distribution is closely related to the cultivated fields of a garrison of military immigrants of the Ming Dynasty. As the core of military and political affairs of Yunnan, central Yunnan became a region of strong defense and development during the Ming Dynasty. However, western Yunnan, where the migration distribution is 
the most extensive, has a polycentric characteristic. The initial conquest of the Army in Yunnan was the capturing of Qujing. This area became an important checkpoint for East Yunnan, forming a military immigration area in Eastern Yunnan for Han migrants. The main traffic line from Yunnan to the interior is located in northeastern Yunnan; therefore, this area contains the inner core Han settlements.

The development of Biantun culture is a microcosm of the gradual integration of the Han nationality and border minority nationalities. Initially, Yunnan was almost a fully agricultural society with low productivity. During the Han and Jin dynasties, the prefectures and counties of the central dynasty increased in Yunnan and the first wave of Han migration occurred. This had a significant impact on the social structure and culture of the region. Subsequently, the Biantun culture continued to develop through several dynasties, and especially during the Ming and Qing dynasties.

To strengthen the rule of native ethnic groups in Yunnan, the rulers of successive dynasties continuously expanded the living areas of Han immigrants, and concurrently spread the Han culture and implemented the policy of Sinicization. This policy promoted cultural exchange and integration between the Han people and native peoples of Yunnan to some extent; however, it was a gradual and unbalanced process. The density map of BTT clearly shows the spatial development of this process. The integration degree between central and north-eastern Yunnan Province is high, whereas that among the northwest, southeast, and southwest areas is low.

Based on analysis of the formation conditions of the BTT, the settlement of Han immigrants with a certain scale was the basis for the increase in BTT, particularly in areas that were suitable for agricultural development and production. Owing to their primitive lifestyle, local ethnic minorities in Yunnan were mainly distributed in mountainous areas far from towns; thus, there is a clear spatial difference between the BTT and ethnic minority toponym cluster regions. The high value regions of the result of KDE of ethnic minority toponyms were extracted in this study. Compared with the distribution of BTT (Fig. 3), there are obvious differences in the distribution of the two types of toponyms. The cluster regions of BTT are mostly distributed in the basins of the central, eastern, western, and northeastern regions; ethnic minority toponyms mainly occur in marginal areas, and mostly in hilly and mountainous areas. The results are consistent with the literature and history records (Lu 1999)

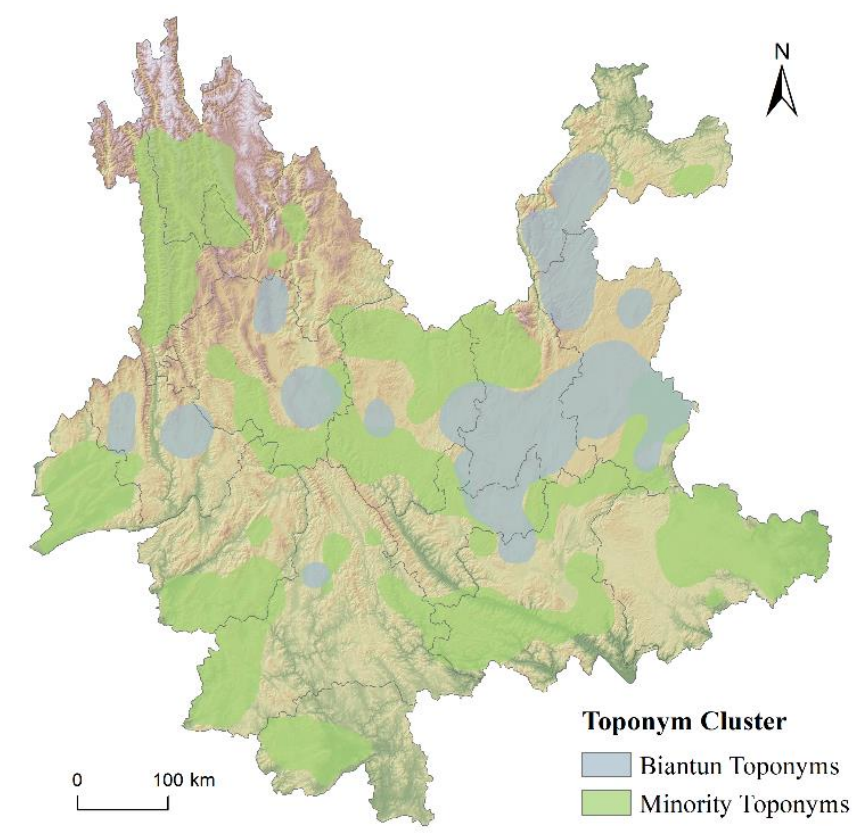


Fig.3 Cluster regions of Biantun toponyms (BTT) and minority toponyms

The Getis-Ord-Gi* statistic takes in attribute values and spatial weights in order to determine statistical significance with a z-score. This z-score is used to determine where high or low concentrations of values are spatially clustered. For statistically significant positive z-scores, the larger the $z$-score, the more intense the clustering of high values (hot spot). For statistically significant negative z-scores, the smaller the z-score, the more intense the clustering of low values (cold spot). Fig. 4 shows the results of the EHSA Z_score (hot spot) in the four periods of BTT. The red area is the hot spot area and the area where the BTT gather.

Fig.4 Emerging hot spot analysis z-score

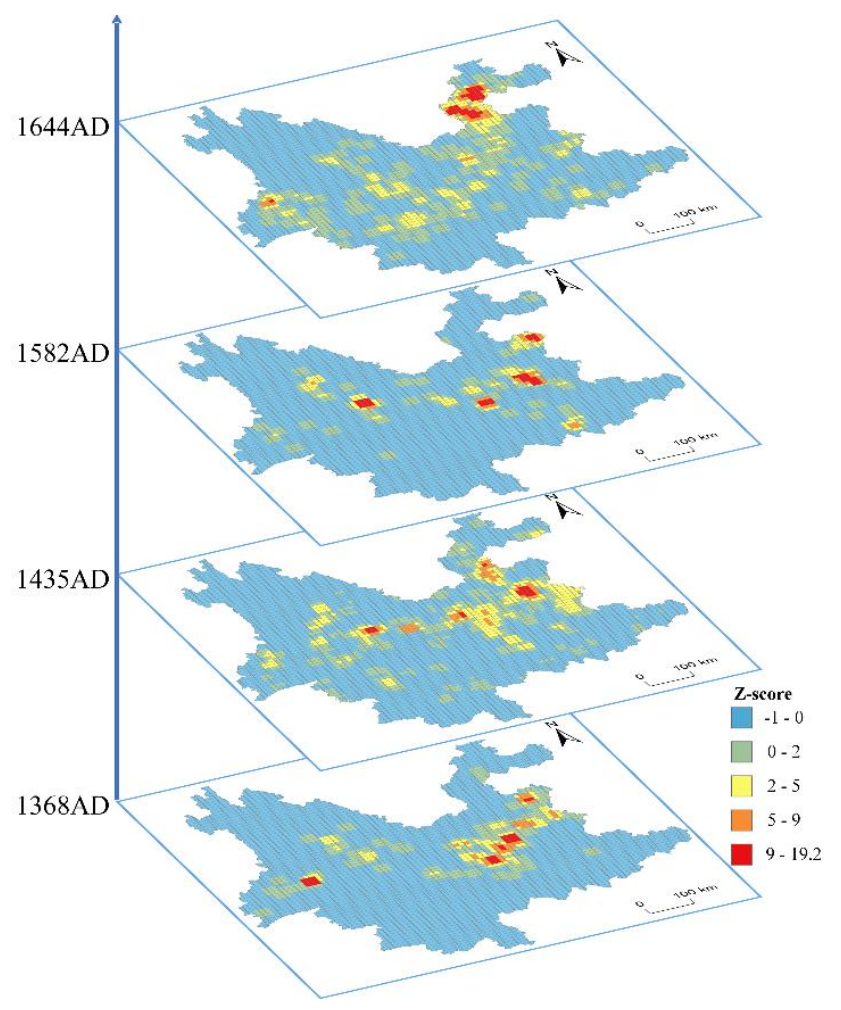

Fig. 5 shows the SDE of BTT points in each period. Although place names found in earlier eras still exist in later eras, the calculation of the geometric center of each era was based on new place names to analyze the distribution characteristics of new place names in each era more clearly. 


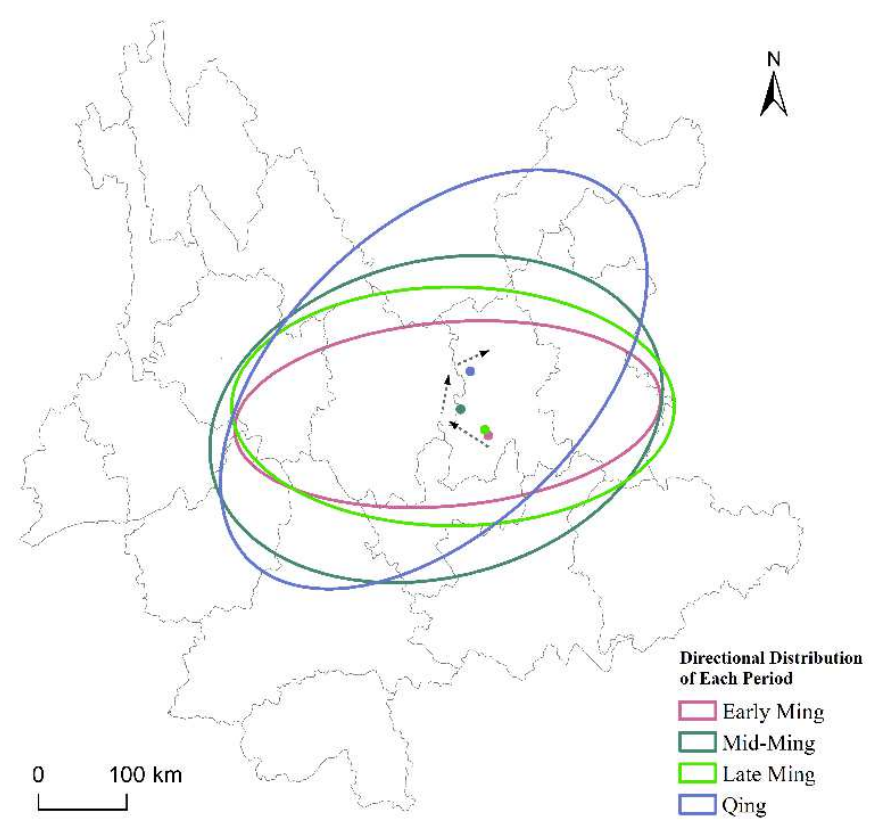

Fig.5 Directional distribution of Biantun toponyms (BTT) in the four periods, arrows indicate the direction change of the distribution of toponyms

From Fig. 4 and Fig. 5, the clustering center of place names for the four periods are distributed in the west of Kunming, which is center of Yunnan Province. Compared with the early Ming Dynasty, the distributions of place names in the next three periods show further expansion. The BTT distribution evolved from the center of Yunnan Province to surrounding areas over time, gradually expanding from central towns and integrating with indigenous peoples.

From the early to middle Ming Dynasty, the distribution of place names was from the southwest to the northeast. In the middle and later periods of the Ming Dynasty, the clustering center of toponyms developed to the southeast, and the distribution direction was west to east. From middle to late periods of the Ming Dynasty, there is no significant change in the distribution of the clustering center of toponyms and the distribution direction showed east-west horizontal development. By the Qing Dynasty, the distribution direction had clearly developed to the northeast. The BTT in each period differed significantly, indicating that the borderland policies in Yunnan Province differed in the four periods.

\section{Spatiotemporal evolutionary characteristics of BTT and Biantun cultural landscape}

Fig. 6 shows the spatiotemporal changes in population during each dynasty. Maps show the number of people in a $9 \mathrm{~km} \times 9 \mathrm{~km}$ grid cell, obtained from the history of the global environment (HYDE) database. The low population in the early Ming dynasty may reflect the unstable situation in Yunnan, which may have made it difficult to count the actual population. In the middle Ming Dynasty, there was a large increase and expansion in both the number of people and spatial then distribution, which was possibly caused by a delay in the population statistics relative to the actual population. 


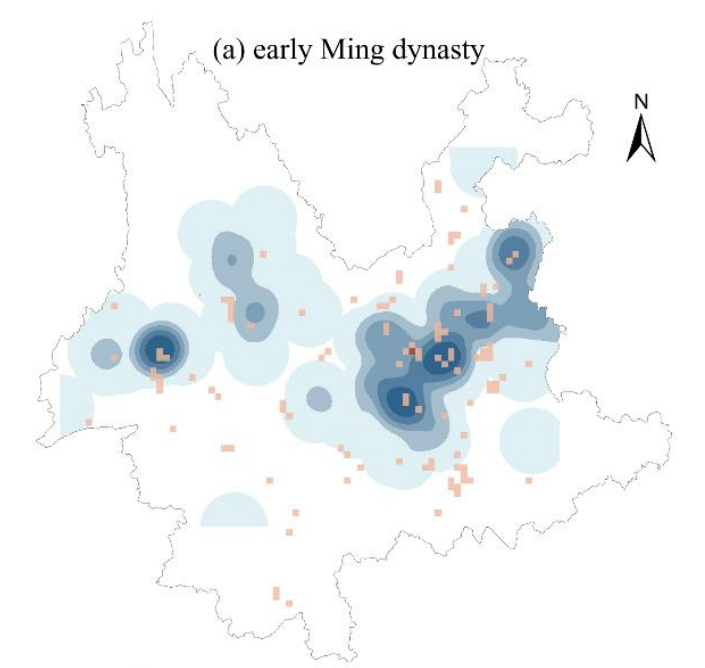

(c) late Ming dynasty

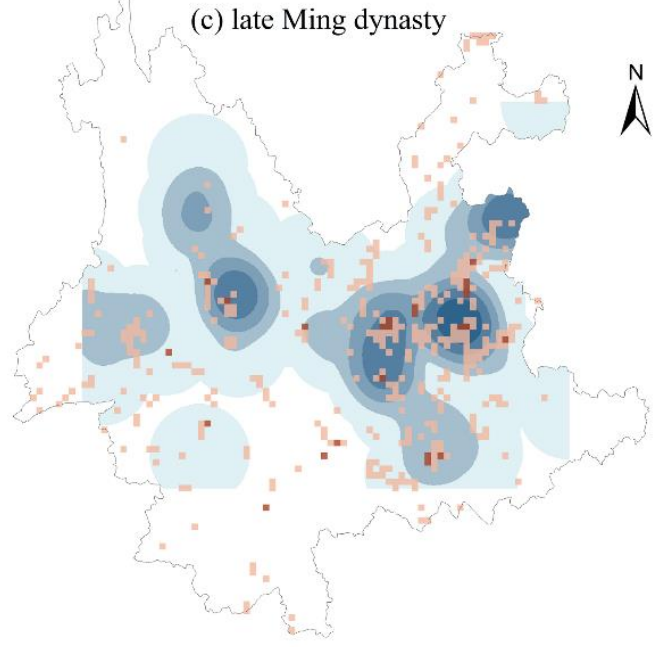

Density of toponyms

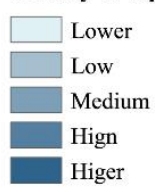

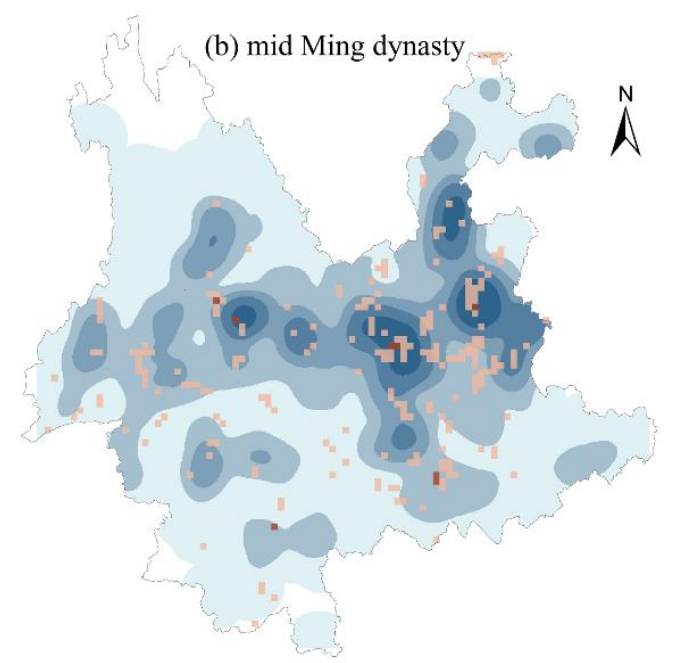

(a) Qing dynasty

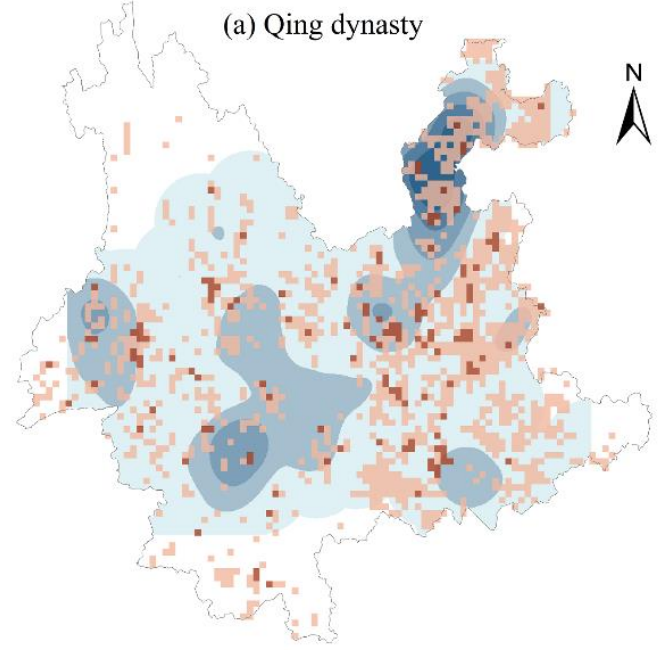

Fig.6 Spatiotemporal evolution of Biantun toponyms (BTT) and population in Yunnan Province

As shown in Fig. 6, the population density of central, western, and northeastern Yunnan increased significantly from the early to middle periods of the Ming Dynasty, which is consistent with the large number of military immigrants moving to Yunnan. The distributional area is also consistent with the garrisons established in the early period of the Ming dynasty. In the middle and late periods of the Ming Dynasty, as Han immigrants entering Yunnan formed stable settlements, the population density increased significantly, and the distribution range expanded from the center to ethnic minority areas. The integration of various ethnic groups in frontier areas during the Qing Dynasty was strengthened compared with the previous generation. Many Han migrants expanded their families in Yunnan. The official system and phenomenon of Shangtun also significantly increased the number of immigrants who moved to Yunnan.

The highest density of BTT was mainly distributed in the Qujing-Kunming-Yuxi area during the early Ming Dynasty. Ming Dynasty policy on the defense of towns in Yunnan began first in the 
hinterlands of central Yunnan; this area also became the earliest named area of the BTT. In the middle period of the Ming Dynasty, the BTT distribution expanded to western, northeastern, and southeastern Yunnan and extended from the suburbs to the outskirts of towns. Various regulations were established in this era. The immigration settlement area was essentially formed and most BTT were derived and named during this period. In the late period of the Ming Dynasty, there were no significant changes in the geographical names of the frontiers. It was common to use the surname of the chief military officer for the names of newly added Tuntian sites at lower levels.

By the Qing Dynasty, the distribution had developed towards intermontane basins, mid-mountain, and mountainous areas. There were many uprisings and anti-aggression struggles during Qing rule and a considerable number of military immigrants remained in Yunnan. The turning point in immigration, the Shangtun phenomenon, left a large number of settlements in Yunnan.

Based on the spatiotemporal distribution of population and BTT in each period, the evolutional relation between Han migration and the BTT was established. The expansion and evolution of distribution in space and time were largely consistent. The large numbers of Ming Dynasty Han immigrants who moved to the remote regions resulted in greater prosperity Biantun culture, as reflected in the place names. The evolution of the spatial distribution of toponyms also evolved with the development in Tuntian regions; from the central hinterland of Yunnan, it gradually extended away to marginal mountain areas and penetrated into ethnic minority areas.

\section{Spatial characteristics of toponymical landscape}

According to Equation (4), calculate and visualize the integration index of each region of point cluster(Fig.7). $H_{i}>0$ means that there are more ethnic minority toponyms than BTT in the region, and vice versa. The closer the $H_{i}$ value is to 0 , the closer the number of the two types of toponyms in the region, the higher the integration degree of the spatial distribution. It shows that the landscape Characteristics of the mixed residence of Han and Minority are more prominent.

The point cluster regions with $H_{i}$ values between 0.6 and -0.6 are mainly distributed in Dali, Chuxiong-Kunming-Qujing area, and Baoshan, Yuxi, Zhaotong, etc are also distributed. This is similar to the result of kin Fig. 2 (b), which corresponds to the extremely unbalanced settlement distribution of Han immigrants in Yunnan in Ming Dynasty. When Yunnan was suppressed in the early Ming Dynasty, the imperial court took the strategy of occupying the central cities and towns first, conquering Kunming, Dali, Chuxiong, Lin'an, Qujing and other military and political towns, then station troops to open up wasteland. The newly built military and political towns became the most important settlements of Han immigrants in Yunnan in the early Ming Dynasty, and constantly absorbed other kinds of immigrants to settle in the cities ( $\mathrm{Lu}$ 1999). Immigrants are mainly distributed in towns and in basin of Tuntian, The Han immigrants who settled in the Fort and Sentry on the traffic road in the remote mountainous area were scattered. From the perspective of toponymic landscape, In Dali, Chuxiong, Kunming, Qujing, and Baoshan (called Jinchi in the Ming Dynasty), there are more cluster regions that are dominated by BTT. Lin'an (Jianshui) district presents the spatial distribution characteristics of minority toponyms are the majority. The deployment of the Ming Dynasty's immigrants to garrison Yunnan is reflected in the distribution of geographical names.

As a result, the ethnic integration in the central towns and the basin districts will be dominated by sinicization, while that Han immigrants settled in mountainous and remote areas will integrate into ethnic minorities. The spatial characteristics of the index of toponyms integration degree calculated in this paper show this, and the visualization results show the landscape differences of the integration degree of the two kinds of toponyms. 


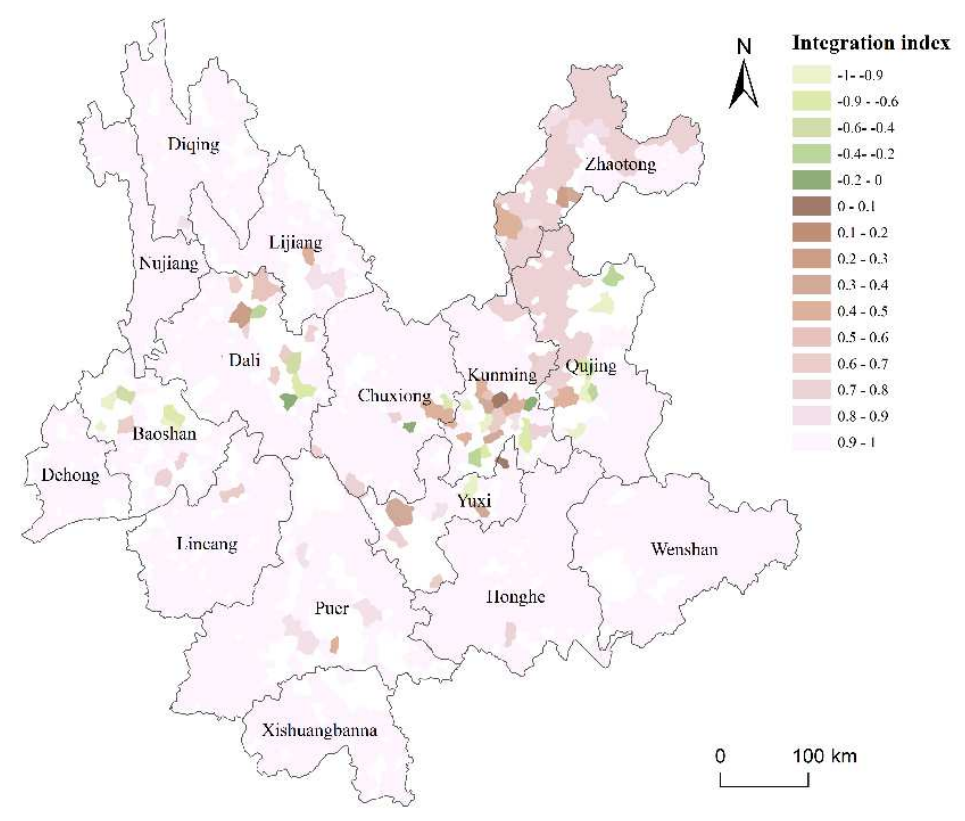

Fig.7 Spatialization results of integration index $\left(H_{i}\right)$, blank areas are areas where toponyms are distributed discretely

\section{Conclusions}

Place names are physical carriers and witnesses of the Biantun culture. They retain the process of mutual influence, penetration, and absorption between the cultures of the Central Plains and border region. However, with the development of urbanization and the replacement of place names, some historical place names are facing extinction. This has a significant impact on the protection of traditional landscapes and local historical culture and implies that investigations of the development and historical significance of Biantun culture lack physical elements. Based on GIS spatial analysis, the course of historical development of place names can be intuitively understood, and, in turn, the development of early Han immigration and ethnic integration. The results of this study provide a reference for the protection of toponymical landscape.

As a frontier region, Yunnan represents the origin and development of the Biantun culture. The migration of military Hans during the Ming and Qing dynasties and a large number of commercial immigrants in the Qing Dynasty contributed to the prosperity and development of Biantun culture in Yunnan and the genesis of a large number of BTT. Historically, the BTT began to develop in the early periods of the Ming Dynasty. Yunnan was stable in the middle periods of the Ming Dynasty, and a large number of military villages were named. In the later periods of the Ming Dynasty, a small number of names were generated. Spatially, the distribution of the BTT extends from the Kunming-Qujing area to the western, eastern, southwestern, and north-eastern regions of Yunnan, developing from the suburbs of central towns to the intermontane basins and mountainous areas.

National integration is an important prerequisite for the development of Biantun culture. Han immigrants and ethnic minorities live together and interact with each other. Among them, the more developed production technology and the progress of cultural education in the new immigration area will inevitably have a strong impact on the surrounding area, promote the common progress and development of the socio-economic culture of all nationalities in the region. Eventually formed the 
Biantun culture of the Han culture of the Central Plains and the local minority cultures blend with each other. The integration index proposed in this study measures the integration degree of spatial distribution of BTT and ethnic minority toponyms, and extracts BTT cluster distribution regions, so as to provide spatial data reference for the development and protection of Biantun cultural resources.

Our quantitative analysis of the spatiotemporal distribution and evolution of Yunnan BTT can be used as a basis to study the origin and development of the Biantun culture and to explore the value of Biantun culture and its socio-economic impact on future generations. In addition, it is imperative to discover and protect historical elements (buildings, streets, rivers) and intangible cultural heritage, such as the human landscape and traditional crafts. However, some place names in the study area lack detailed records, and data are based on today's place names; in time, many historic place names have been lost or changed. The screening of BTT can further identify and determine place name descriptions at a semantic level ${ }^{28}$. Further study to link data from social sciences with a GIS approach to classify BTT will improve our knowledge of human influence on the toponymical landscape.

360 Funding: This research was funded by the National Natural Science Foundation of China (Grant 361 No. 41961064); Yunnan Department of Science and Technology application of basic research project 362 (Grant No. 202001BB050030).

Acknowledgments: The authors would like to thank anonymous reviewers and the editors for their constructive comments and suggestions. The authors also would like to thank Editage (www.editage.cn) for English language editing

Author contributions: Zhao, F.: contributed to the conception of the study; Cai, J., Zhang, C.: performed the data analyses and wrote the manuscript; Luan, G.,Fu, Y., Xie Z.: contributed to analysis and manuscript preparation.

Declaration of interest statement: The authors declare no conflict of interest.

\section{References}

$1 \mathrm{Lu}, \mathrm{R}$. Changes and Blending-Studies on the Han Immigrants of Yunnan in the Ming Dynasty, Yunnan University, (1999).

2 Zhang, Z. The Spread and Formation of Biantun Culture in Yunnan. Academic Research, 112-116 (2013).

3 Zhu, H. Analysis on the Place Names in Minority Languages in Yunnan. Yunnan Geographic Environment Research, 11-22 (1994).

4 Dai, H. Studies on the Place name of Dai languagein Sipsuong Bhaannaa, Minzu University of China, (2004).

5 Luo, W., F., H. J. \& Wang, F. Terrain characteristics and Tai toponyms: a GIS analysis of Muang, Chiang and Viang. Geojournal 75, 93-104 (2010).

6 Wang, F., Zhang, L., Zhang, G. \& Hong, Z. Mapping and spatial analysis of multiethnic toponyms in Yunnan, China. Cartography \& Geographic Information Science 41, 86-99 (2014).

7 Fagúndez, J. \& Izco, J. Diversity patterns of plant place names reveal connections with environmental and social factors. Applied Geography 74, 23-29 (2016a).

8 Fagúndez, J. \& Izco, J. Spatial analysis of heath toponymy in relation to present-day heathland distribution. International Journal of Geographical Information Science 30, 51-60 (2016b). 
9 Claudia, P., Luisa, C., Vitale, D. \& Ignazio, C. Phyto-toponyms of Arbutus unedo L. and their distribution in Sardinia (Italy). Plos One 12, e0181174 (2017).

10 Li, J., Xu, H., Liu, W., Wang, D. \& Zhou, S. Spatial Pattern Evolution and Influencing Factors of Cold Storage in China. Chinese Geographical Science 30, 505-515, doi:10.1007/s11769-020-1124-1 (2020).

11 Turk, A. \& Stea, D. David Mark's contribution to ethnophysiography research. International Journal of Geographical Information Science 28, 1246-1263 (2014).

12 Wang, F., Wang, G., John, H. \& Wei, L. Sinification of Zhuang place names in Guangxi, China: a GIS - based spatial analysis approach. Transactions of the Institute of British Geographers 37 (2012).

13 Wang, F., Wang, G. \& Li, X. GIS-based spatial analysis of Zhuang place names in Guangxi, China. Geographical Research 32, 487-496 (2013).

14 Qian, S., Kang, M. \& Weng, M. Toponym mapping: a case for distribution of ethnic groups and landscape features in Guangdong, China. Journal of Maps 12, 1-5 (2016).

15 Wang, Y. et al. Spatial-temporal characteristics and causes of changes to the county-level administrative toponyms cultural landscape in the eastern plains of China. PLoS One 14, e0217381, doi:10.1371/journal.pone.0217381 (2019a).

$16 \mathrm{Lu}, \mathrm{R}$. The Development of the Chinese Place-names in Yunnan and Changes of the Ethnic Composition. Journal of Yunnan Nationalities University 22, 63-68 (2005).

$17 \mathrm{Lu}, \mathrm{R}$. The Distribution and Development of the Han Immigrant's Settlement in Yunnan during the Ming Dynasty. Journal of Chinese Historical Geography, 74-83 (2006).

18 Buscaldi, D. \& Rosso, P. A conceptual density-based approach for the disambiguation of toponyms. International Journal of Geographical Information Science 22, 301-313 (2008).

19 Cheshire, J. A. \& Longley, P. A. Identifying spatial concentrations of surnames. International Journal of Geographical Information Science 26, 309-325, doi:10.1080/13658816.2011.591291 (2012).

20 Derungs, C. \& Purves, R. S. From text to landscape: locating, identifying and mapping the use of landscape features in a Swiss Alpine corpus. International Journal of Geographical Information Science 28, 1272-1293, doi:10.1080/13658816.2013.772184 (2014).

21 Derungs, C. \& Samardžić, T. Are prominent mountains frequently mentioned in text? Exploring the spatial expressiveness of text frequency. International Journal of Geographical Information Science 32, 856-873 (2018).

22 Moncla, L. et al. Mapping urban fingerprints of odonyms automatically extracted from French novels. International Journal of Geographical Information Science 33, 2477-2497 (2019).

23 McDonough, K., Moncla, L. \& Camp, M. v. d. Named entity recognition goes to old regime France: geographic text analysis for early modern French corpora. International Journal of Geographical Information Science 33, 2498-2522, doi:10.1080/13658816.2019.1620235 (2019).

24 Wang, C., Zhang, M. \& Ma, S. A Survey of Natural Language Processing in Information Retrieval. Journal of Chinese information processing 21 (2007).

25 ESRI. How Emerging Hot Spot Analysis works, $<$ https://desktop.arcgis.com/en/arcmap/10.3/tools/space-time-pattern-miningtoolbox/learnmoreemerging.htm $>$ (2016a).

26 ESRI. How create space time cube works, 
$<$ https://desktop.arcgis.com/en/arcmap/10.3/tools/space-time-pattern-miningtoolbox/learnmorecreatecube.htm> (2016b).

27 Deng, M., Liu, Q., Cheng, T. \& Shi, Y. An adaptive spatial clustering algorithm based on delaunay triangulation. Computers, Environment and Urban Systems 35, 320-332, doi:10.1016/j.compenvurbsys.2011.02.003 (2011).

28 Stokes, N., Li, Y., Moffat, A. \& Rong, J. An empirical study of the effects of NLP components on Geographic IR performance. International Journal of Geographical Information Science 22, 247-264, doi:10.1080/13658810701626210 (2008). 


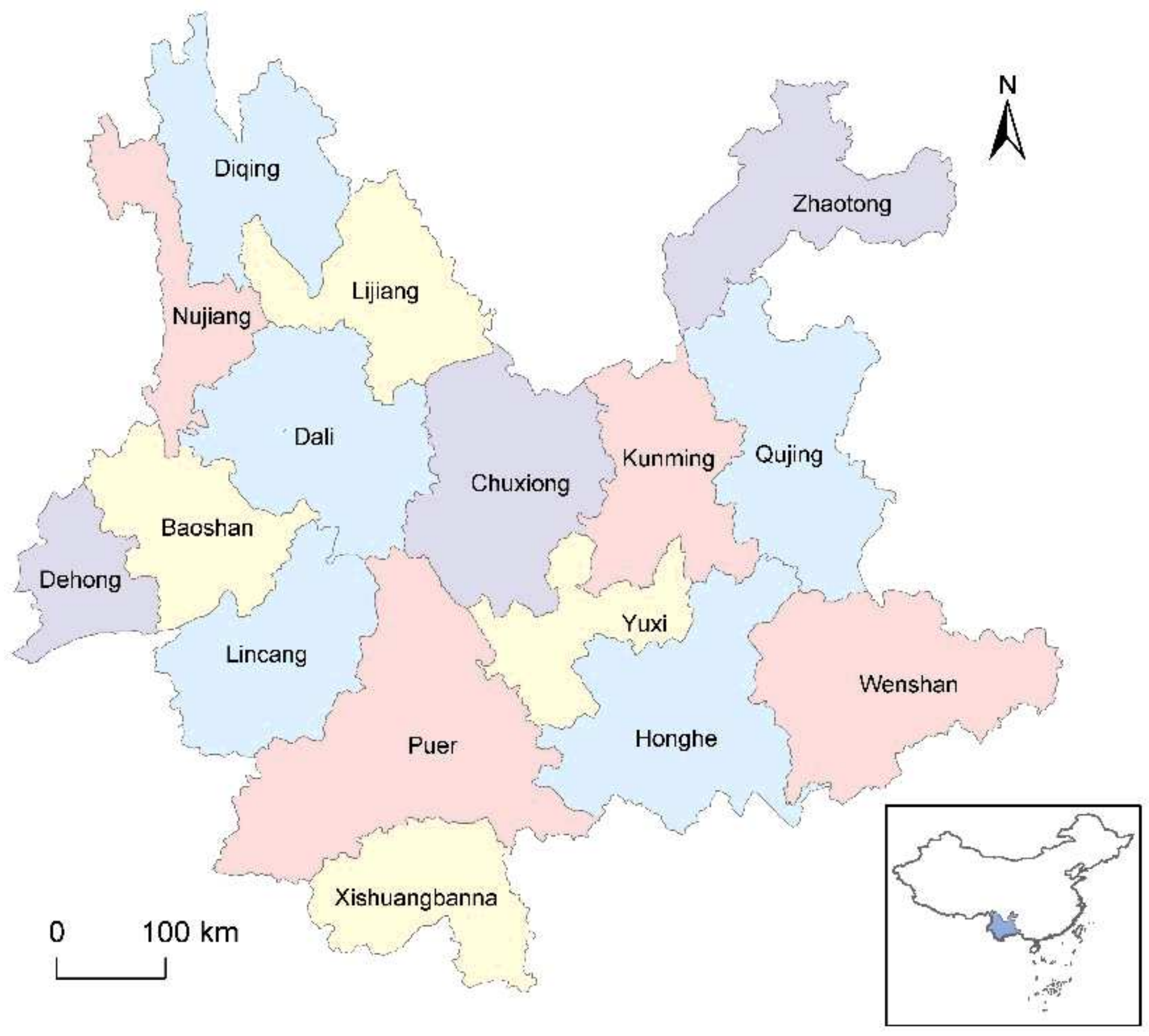

\section{Figure 1}

Location of Yunnan Note: The designations employed and the presentation of the material on this map do not imply the expression of any opinion whatsoever on the part of Research Square concerning the legal status of any country, territory, city or area or of its authorities, or concerning the delimitation of its frontiers or boundaries. This map has been provided by the authors. 

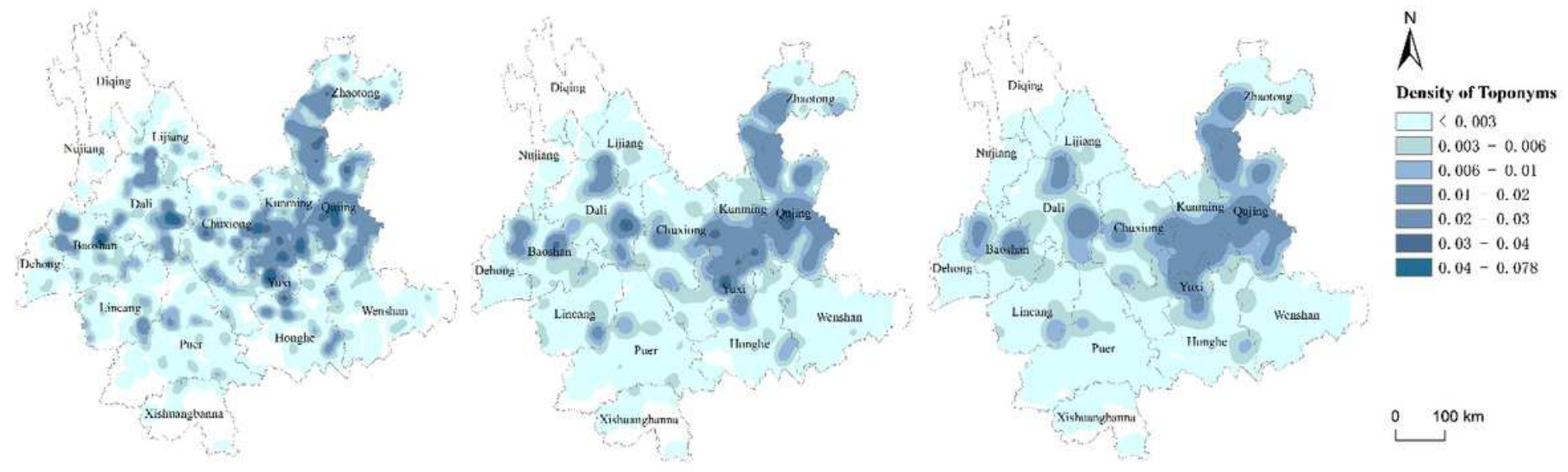

Figure 2

Kernel density of BTT with bandwidth of $20 \mathrm{~km}, 30 \mathrm{~km}, 40 \mathrm{~km}$ Note: The designations employed and the presentation of the material on this map do not imply the expression of any opinion whatsoever on the part of Research Square concerning the legal status of any country, territory, city or area or of its authorities, or concerning the delimitation of its frontiers or boundaries. This map has been provided by the authors. 


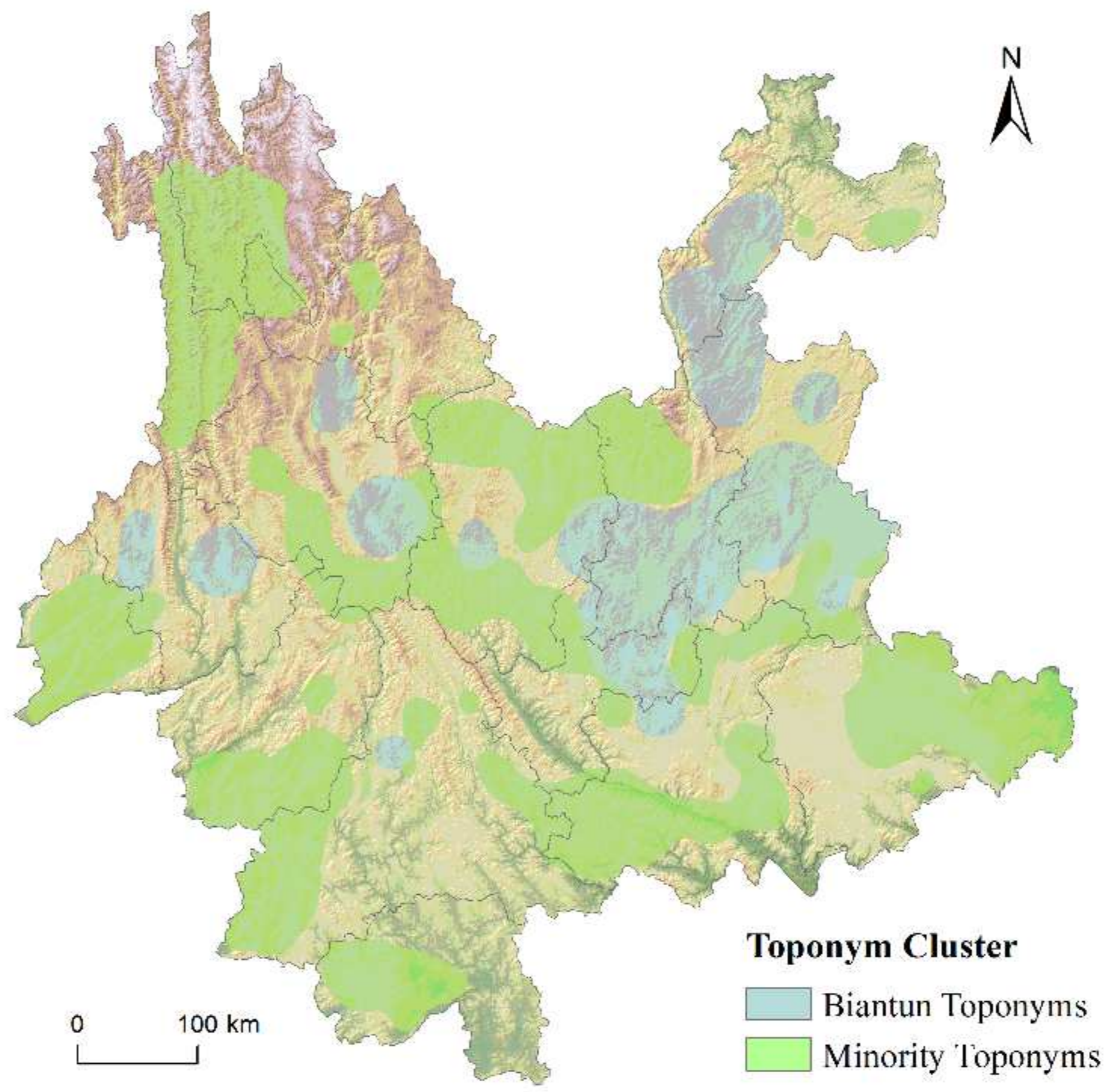

\section{Figure 3}

Cluster regions of Biantun toponyms (BTT) and minority toponyms Note: The designations employed and the presentation of the material on this map do not imply the expression of any opinion whatsoever on the part of Research Square concerning the legal status of any country, territory, city or area or of its authorities, or concerning the delimitation of its frontiers or boundaries. This map has been provided by the authors. 


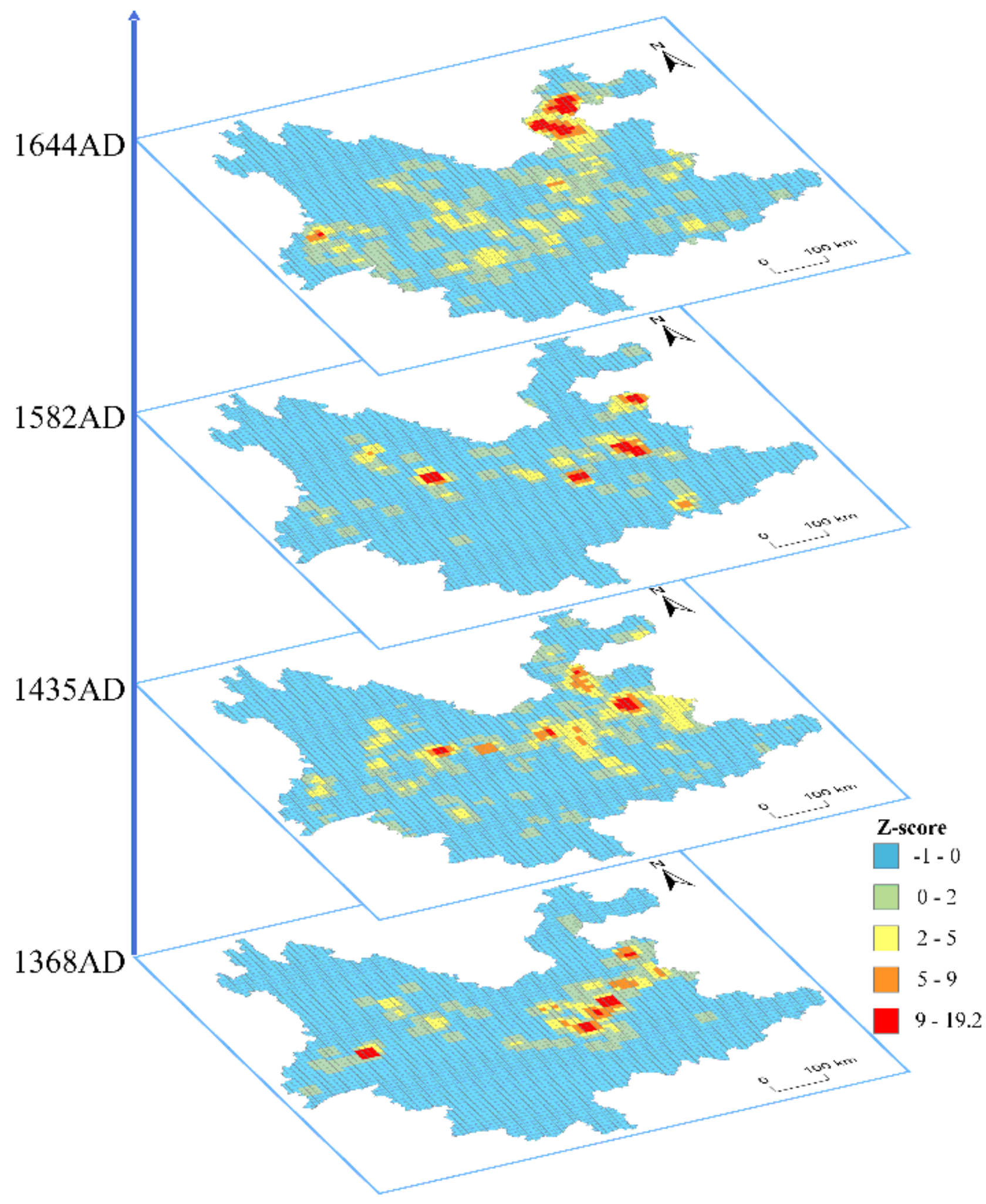

\section{Figure 4}

Emerging hot spot analysis z-score Note: The designations employed and the presentation of the material on this map do not imply the expression of any opinion whatsoever on the part of Research Square concerning the legal status of any country, territory, city or area or of its authorities, or concerning the delimitation of its frontiers or boundaries. This map has been provided by the authors. 


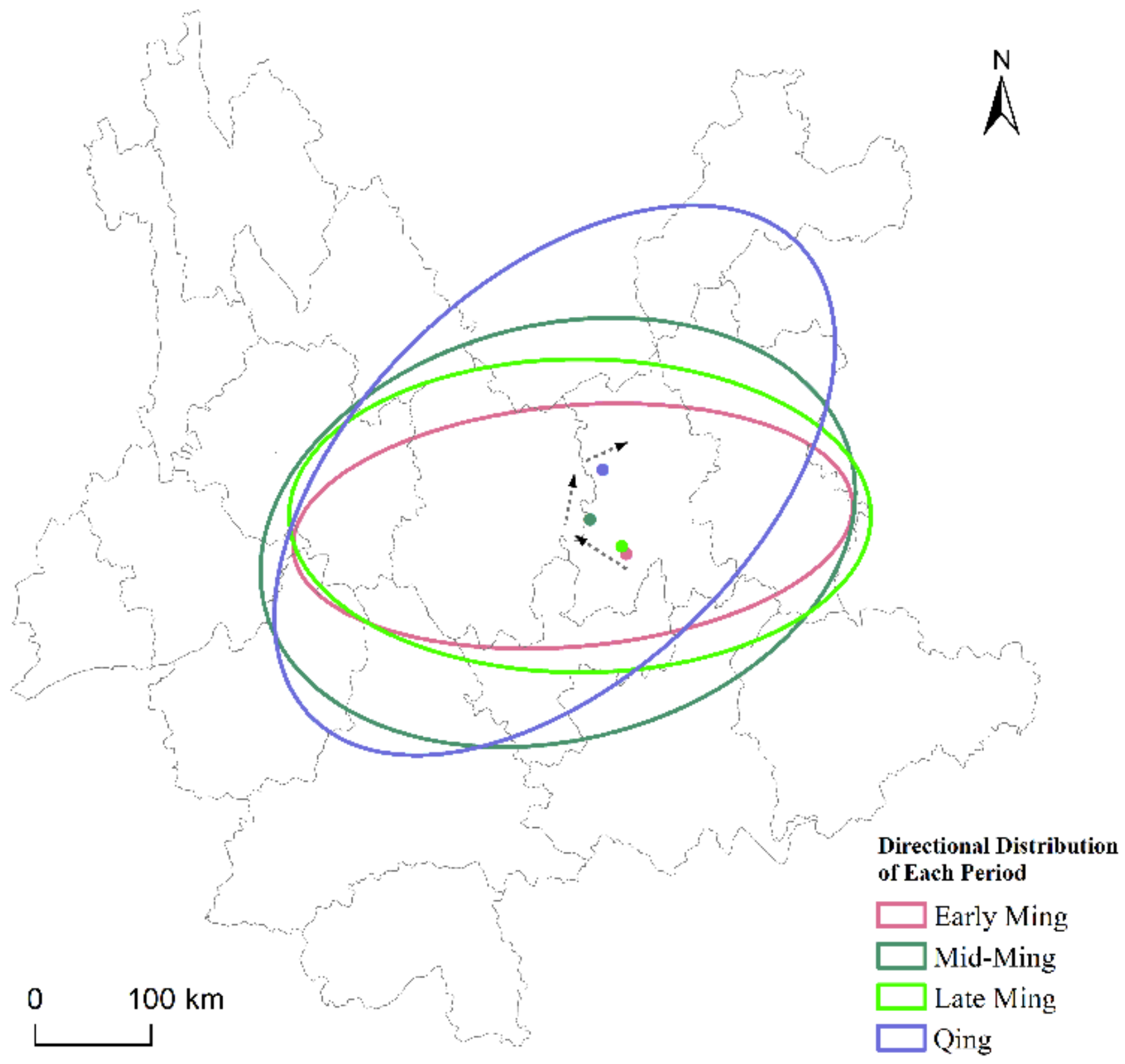

Figure 5

Directional distribution of Biantun toponyms (BTT) in the four periods $₫$ arrows indicate the direction change of the distribution of toponyms Note: The designations employed and the presentation of the material on this map do not imply the expression of any opinion whatsoever on the part of Research Square concerning the legal status of any country, territory, city or area or of its authorities, or concerning the delimitation of its frontiers or boundaries. This map has been provided by the authors. 

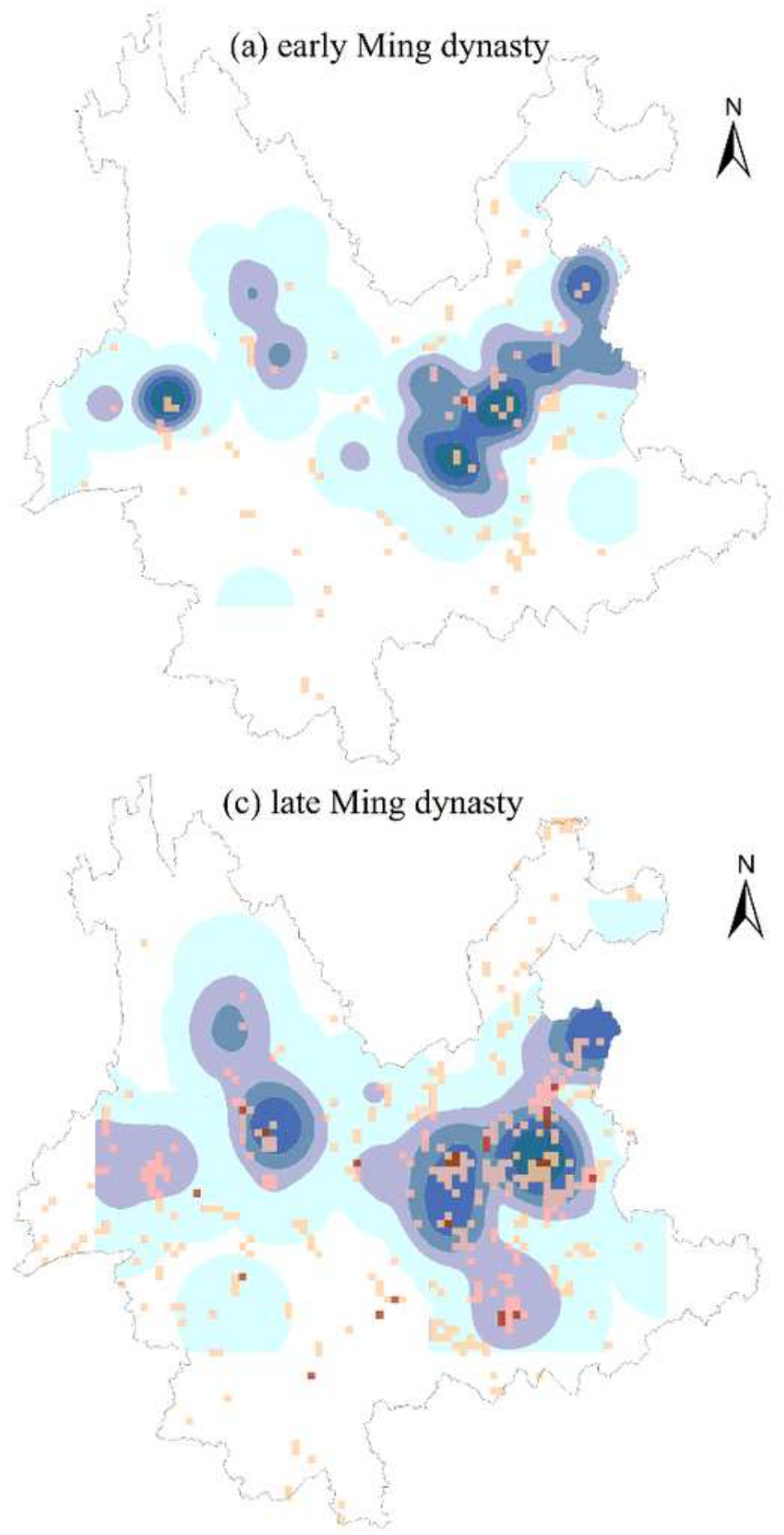

(b) mid Ming dynasty

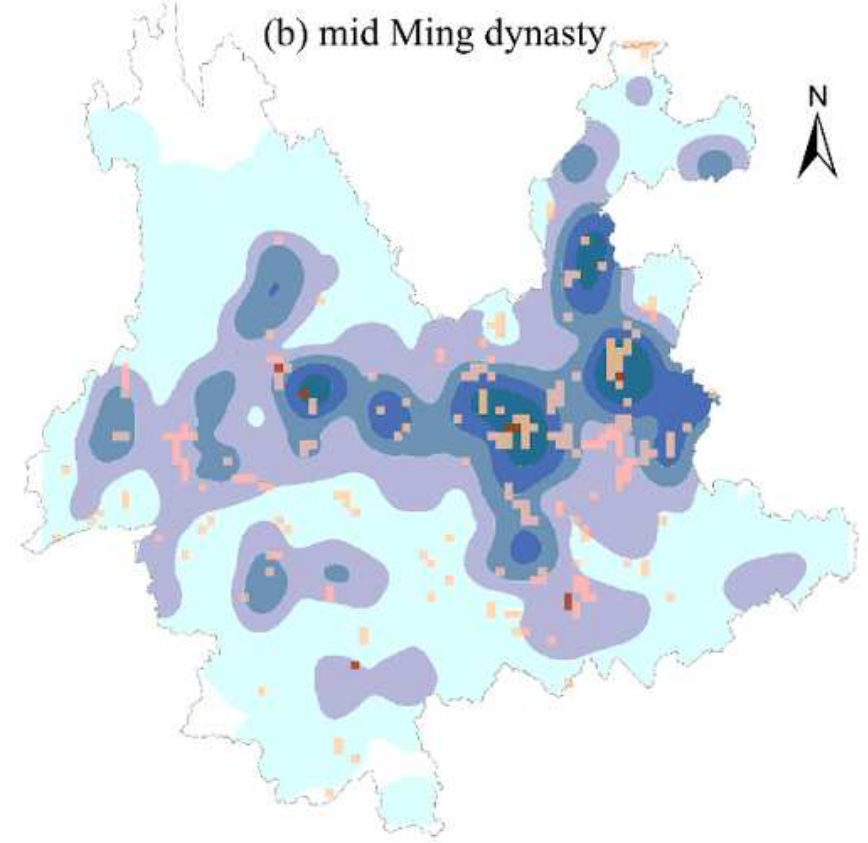

(a) Qing dynasty

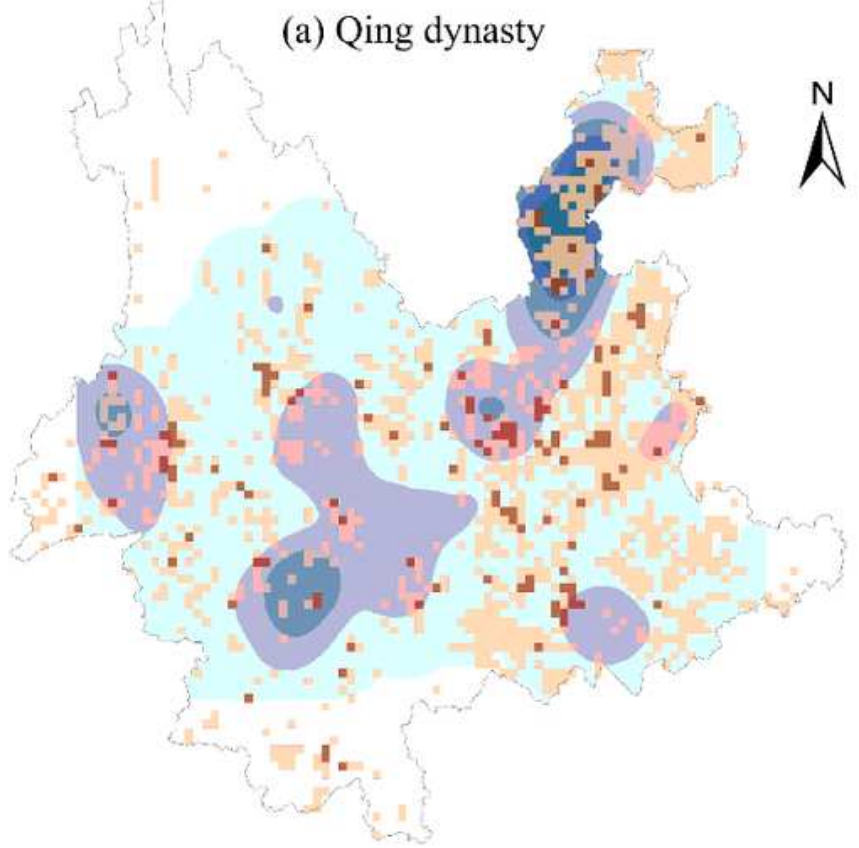

\section{Density of toponyms}
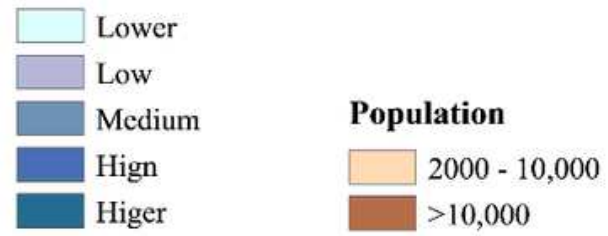

$0 \quad 100 \mathrm{~km}$

\section{Figure 6}

Spatiotemporal evolution of Biantun toponyms (BTT) and population in Yunnan Province Note: The designations employed and the presentation of the material on this map do not imply the expression of any opinion whatsoever on the part of Research Square concerning the legal status of any country, territory, city or area or of its authorities, or concerning the delimitation of its frontiers or boundaries. This map has been provided by the authors. 


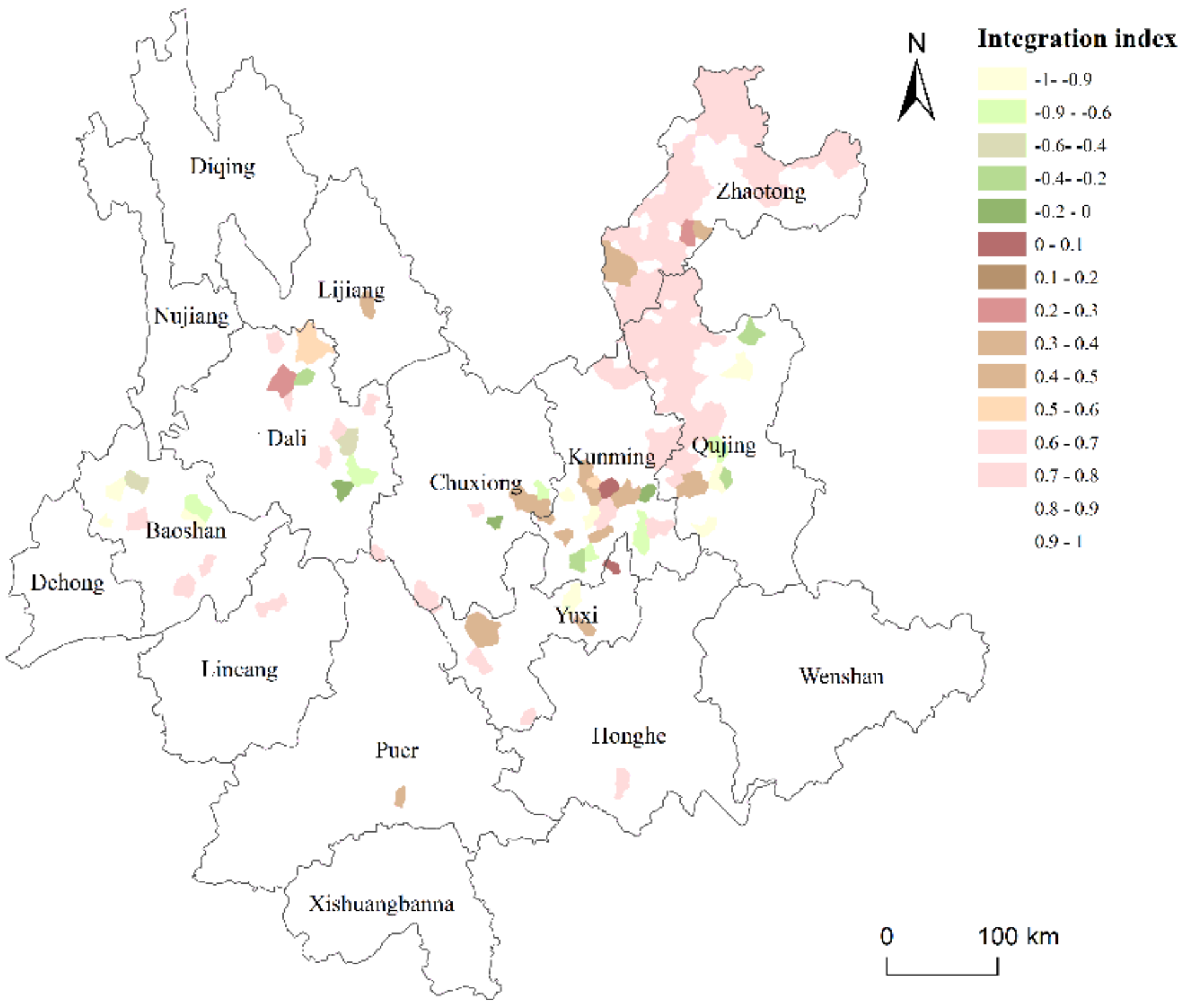

\section{Figure 7}

Spatialization results of integration index $(\mathrm{Hi})$, blank areas are areas where toponyms are distributed discretely Note: The designations employed and the presentation of the material on this map do not imply the expression of any opinion whatsoever on the part of Research Square concerning the legal status of any country, territory, city or area or of its authorities, or concerning the delimitation of its frontiers or boundaries. This map has been provided by the authors. 